\title{
Increasing the number of available ranks in virus taxonomy from five to ten and adopting the Baltimore classes as taxa at the basal rank
}

\author{
Alexander E. Gorbalenya ${ }^{1,2}$ (1) \\ Received: 2 March 2018 / Accepted: 14 May 2018 / Published online: 26 June 2018 \\ (c) The Author(s) 2018
}

\begin{abstract}
This opinion article makes a case for increasing the number of ranks used in virus taxonomy from the current five to ten (as are used to classify cellular life forms) and placing the Baltimore classes in the proposed basal rank of domain. These suggestions aim at initiating the process of accommodation of Baltimore classes in virus taxonomy and extension of the virus taxonomy scale to encompass also the most distant relationships.
\end{abstract}

The International Committee on Taxonomy of Viruses (ICTV) oversees the development of hierarchical virus taxonomy according to the rank structure introduced in 1970 and expanded on several occasions [2]. Currently, it encompasses five ranks, including Order, Family, Subfamily, Genus and Species, in decreasing levels of virus diversity (Virus Code 3.2). These ranks were adopted from those used in the modern version of the Linnaean taxonomy of cellular life forms (virus hosts), which recognizes eight major ranks and may include additional optional ranks. The ranks lacking in virus taxonomy are predominantly above the Order rank (Table 1). Apparently, the limited number of ranks were adopted in virus taxonomy because, at the time, they were sufficient for classifying virus diversity, although a system to embrace the viral world as a whole was already proposed [21]. When the ICTV was founded, only a few dozen viruses from mostly humans, economically important animal and plant hosts and a few bacteria had been identified [29], and there was no indication of the coming grand scale of virus discovery that we are experiencing nowadays (e.g. [4, 12, 28]).

This contemporary taxonomic structure with its modifications has served virology and virologists for fifty years,

Handling Editor: Sead Sabanadzovic.

Alexander E. Gorbalenya

a.e.gorbalenya@lumc.nl

1 Department of Medical Microbiology, Leiden University Medical Center, 2300, RC, Leiden, The Netherlands

2 Faculty of Bioengineering and Bioinformatics, Lomonosov Moscow State University, 119899 Moscow, Russia when the number of established virus families increased from two to more than one hundred and the number of recognized virus species increased by some two orders of magnitude [2]. Also, the number of ranks that were populated increased from the initial two, genus and family, to the current five, including also species, subfamily, and order, as our knowledge about the natural diversity of viruses and our understanding about the complexity of relations have increased dramatically over these years. (Regretfully, only the introduction and development of the species rank have been extensively documented [26, 27]).

The roots of this increased knowledge and rank expansion could be traced back to the advent of virus genome sequencing and comparative virus genomics, introduced in the end of 1970s and beginning of 1980s [6, 13, 23, 25]. Comparative virus genomics revealed sequence conservations at the family level and above, that had previously been considered unattainable (reviewed at the time in [7, 24]). Many taxa at different ranks, which were established using phenotypic characteristics, were revised, as a result. Now, with the large-scale discovery of viruses in diverse hosts and habitats through genome sequencing, and the increased sophistication of computational methods for the quantification of phylogenetic relationships, it is becoming increasingly evident that the ICTV taxonomy rank structure is insufficient to accommodate properly the emerging scale of virus diversity and the complexity of virus phylogeny. This inconsonance also becomes a practical matter since the ICTV is about to formally recognize the on-going shift from phenotypic- to genomic-based virus taxonomy. (Which it did [3], after the taxonomy proposal underlying this article was submitted). 
Table 1 Rank structure of Virus Taxonomy, currently used and proposed

\begin{tabular}{lll}
\hline Rank & Currently used $^{1}$ & Proposed $^{1}$ \\
\hline 1 & & Domain \\
2 & & Kingdom \\
3 & & Phylum \\
4 & & Class \\
5 & Order & Order \\
6 & & Suborder \\
7 & Family & Family \\
8 & Subfamily & Subfamily \\
9 & Genus & Genus \\
10 & Species & Species \\
\hline
\end{tabular}

${ }^{1}$ Major ranks are left indented

Below, I list several arguments in favor of adopting an expanded version of the rank structure of the modern Linnaean taxonomy for virus taxonomy and adoption of the Baltimore groupings in the rank of domain, which might be seen as a revival of the idea put forward by Lwoff, Turnier, and Horne [21]. It should be noted that specific examples given below, predominantly from my research and biased for this reason, are NOT taxonomic proposals but are used to illustrate general principles.

Argument 1 General. The virus host imposes major constraints on virus divergence which effectively links virus and host diversities [15]. Due to the high mutation rate of viruses and the apparent lack of virus-free hosts, it is likely that virus diversity may not be smaller, and is more likely larger than host diversity. Consequently, it could be argued that the number of ranks used to classify viruses should parallel the ranks used to classify hosts, if sufficient virus diversity is available for analysis.

Argument 2 Domain and Class. Virologists recognize the Baltimore classification of viruses into six (or seven occasionally) classes (Fig. 1) [5] at its foundation. However, the term "class" itself is not a formally recognized rank in virus taxonomy [14]. This discrepancy is repeatedly highlighted by many virologists, and it calls for action. It would be worth considering recognizing the Baltimore groupings as taxa of the "domain" rather than class rank, which is basal level of the Linnaean taxonomy that encompasses most distant relationships.

Unlike currently recognized taxa, Baltimore classes were established using purely functional considerations concerning genome type and its expression. Its broad albeit informal use in taxonomy is due to overall (perceived) good

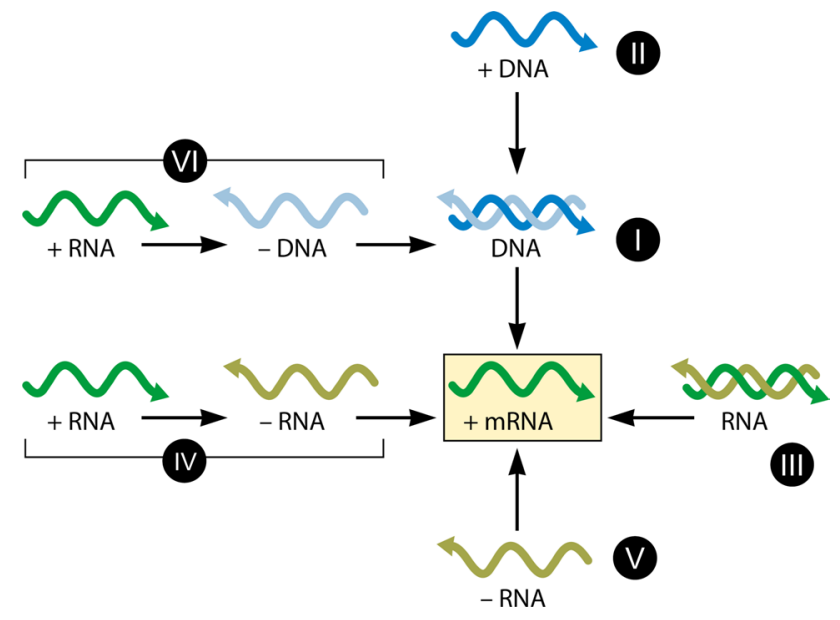

Fig. 1 Baltimore classification and its basis. After Fig. 1 of Ref. [5]. (Modified with permission from Flint et al. 2015, Principles of Virology, 4th Edition, Chapter 1, p. 21;@2015 American Society for Microbiology. Used with permission. No further reproduction or distribution is permitted without the prior written permission of American Society for Microbiology.)

agreement between these classes and taxa that are recognized phylogenetically. However, this correspondence is not universal, as, for instance, was demonstrated for the dsRNA Birnaviridae and the ssRNA + Permutotetraviridae, which form an inter-class monophyletic group [9, 30]. There are few other examples of complex relationship between Baltimore classes and phylogenetic groups.

The formal recognition of Baltimore classes at the basal rank of virus taxonomy would open these newly formed taxa, as any other taxa, for oversight and revision by practitioners under the ICTV auspices. Using the conventional taxonomy proposal framework of creating, dissolving, and moving taxa, and coupling it with evolutionary reasoning and public debate, the placement and composition of the original taxa including Baltimore classes could be refined, and a public record of the revision and its reasoning created. The formal recognition of Baltimore classes as taxa at the basal rank of virus taxonomy would also (re-)define the scale of the entire taxonomy, which is informative for defining scales of other newly created ranks. Combined these changes will contribute to the advancement of virus taxonomy and its use in teaching, research, and practical applications.

Argument 3 Order and above. While the basal rank of virus taxonomy is order, several "super-order" groupings of viruses have been described on phylogenetic grounds. For ssRNA + viruses, they are known as supergroups or superfamilies [7, 8, 24]. For instance, the Picornaviruslike and Alphavirus-like supergroups each include a single order as a subset, Picornavirales [20] and Tymovirales [1], 
respectively, as well as many other more distantly related families. In the case of Picornavirus-like supergroup [16, 20], these families, e.g. Caliciviridae and Potyviridae, share different number of conserved domains and separated by different distances from the Picornavirales, indicating that more than a single additional level above order would be required to accommodate them fully in an hierarchical structure.

This example is not an exception, as was shown by our extensive analysis of the order Nidovirales, which comprises a distinct supergroup of ssRNA + viruses [8]. This order includes two large monophyletic sets of viruses above the family level ("sub-order"), which are known as small and large nidoviruses, respectively [11]. They are recognized using phylogeny of the most conserved proteins and the presence/absence of the replicative riboexonuclease, ExoN, that serves as a marker domain whose presence correlates with genome size [22]. An extra rank between family and order would reflect better the relationship between the phylogeny and the taxonomy of nidoviruses. An alternative solution would be the introduction of an extra rank above the taxa order and elevation of the current nidovirus order to this rank. Since Nidovirales distantly resemble Astroviridae and a subset of Luteoviridae [11] and all these together have sequence affinity to the Picornavirus-like supergroup [8], further additional ranks could be filled to reflect these relationships.

Clearly, the availability of extra levels above the family rank will facilitate the taxonomy development of other, currently less structured supergroups of ssRNA + viruses of plants and animals, and other classes of viruses, which have highly diverse monophyletic groups, e.g. Reoviridae, Mononegavirales, etc.

Argument 4 Family. Using a rigorous method for quantifying the statistical support for clusters and ranks called DEmARC [17], we partitioned the genomic diversity of several RNA virus families into hierarchical classifications. We observed that these classifications included extra level(s) (ranks), whose support was comparable with those of other ranks currently recognized in taxonomy [18]. It could be argued that, at the moment, the extra level(s) in these genetics-based classification of, for example, arteriviruses and filoviruses [19] might have been observed due to the relatively small sampling of viruses in these families ( $<700$ genomes). However, this explanation seems unlikely for the Coronaviridae and, particularly, Picornaviridae [17] families, which are amongst the most well sampled groups of viruses studied. In fact, an extra level supported by DEmARC, below the current genus level and called "subgroup" [10], is used by practicing coronavirologists because of its biological relevance. Although the Linneaen taxonomic structure does not offer extra major levels below the family rank, the availability extra levels above the family rank could be used to improve the correspondence between taxonomy and genome-base classification.

\section{Conclusions}

The current taxonomic rank structure of five levels was developed to accommodate an ever-increasing but still relatively limited virus diversity known to us, at a time when virus discovery was mostly an annual event to celebrate. Now viruses are discovered daily if not hourly. The number of known virus species is expected increase from the current thousands to zillions in the future and their classification will be driven by comparative genomics. To accommodate the complexity of phylogenetic relationships apparent within this fast growing diversity, the virus taxonomic rank structure must be adjusted accordingly, as has already become evident from bioinformatics analysis of few better characterized groups of viruses. Using an expanded version of the Linnaean taxonomic structure of ten ranks (eight canonical plus two optional) will contribute to a better description of virus diversity and improve cross-talk between the taxonomies of viruses and their hosts. The number of these ranks could be revisited and, if necessarily, expanded further in the future. Besides the obvious changes to the Virus Code, the formal recognition of the Baltimore classes at the basal level of virus taxonomy could be the first practical steps in this direction.

Acknowledgements I am indebted to Stuart Siddell and Andrew King for the critical reading of and useful suggestions to the taxonomy proposal 2016.003G.N.v1.VirusTaxonomyRanks (submitted on August 4,2016) that was slightly modified to produce this article with a goal of facilitating discussion of the raised issues. The relevant literature is much larger than the cited, and I apologize to all colleagues for omissions. The Executive Committee of ICTV considered the 2016.003G.N.v1.VirusTaxonomyRanks proposal along with the 2016.001aG.N.v1.ICVCN_new_ranks proposal of Jens H. Kuhn and Andrew Kropinski, who suggested changes to the code to allow introduction of additional ranks in virus taxonomy in an unrestricted manner. The EC-ICTV was receptive to the idea of expanding the number of ranks available in virus taxonomy, as described in this paper, but was divided in respect to the accommodation of Baltimore classes. It created a working group composed of Jens H. Kuhn, Mart Krupovic, Arcady Mushegian, Andrew M. Kropinski, Stuart Siddell, Arvind Varsani, and Alexander E. Gorbalenya to develop the additional ranks idea further. Currently, the EC-ICTV is considering two taxonomy proposals which could be traced to different elements of this article; they will be described in separate manuscripts.

Funding My work was partially supported by Leids Universiteits Fonds, Agreement about Cooperation in Bioinformatics between LUMC and MSU (MoBiLe Program), and EU project EVAg 653316. 


\section{Compliance with ethical standards}

Conflict of interest The author declares that he has no conflict of interest.

Ethical approval This article does not contain any studies with human participants or animals performed by the author.

Open Access This article is distributed under the terms of the Creative Commons Attribution 4.0 International License (http://creativeco mmons.org/licenses/by/4.0/), which permits unrestricted use, distribution, and reproduction in any medium, provided you give appropriate credit to the original author(s) and the source, provide a link to the Creative Commons license, and indicate if changes were made.

\section{References}

1. Adams MJ, Kreuze J, Martelli GP (2012) Order Tymovirales. In: King AMQ, Adams MJ, Carstens EB, Lefkowitz EJ (eds) Virus Taxonomy, Classification and Nomenclature of Viruses. Ninth Report of the International Committee on Taxonomy of Viruses. Elsevier, Academic Press, Amsterdam, pp 901-903

2. Adams MJ, Hendrickson RC, Dempsey DM, Lefkowitz EJ (2015) Tracking the changes in virus taxonomy. Arch Virol 160:1375-1383

3. Adams MJ, Lefkowitz EJ, King AMQ, Harrach B, Harrison RL, Knowles NJ, Kropinski AM, Krupovic M, Kuhn JH, Mushegian AR, Nibert ML, Sabanadzovic S, Sanfacon H, Siddell SG, Simmonds P, Varsani A, Zerbini FM, Orton RJ, Smith DB, Gorbalenya AE, Davison AJ (2017) 50 years of the international committee on taxonomy of viruses: progress and prospects. Arch Virol 162:1441-1446

4. Angly FE, Felts B, Breitbart M, Salamon P, Edwards RA, Carlson C, Chan AM, Haynes M, Kelley S, Liu H, Mahaffy JM, Mueller JE, Nulton J, Olson R, Parsons R, Rayhawk S, Suttle CA, Rohwer $\mathrm{F}$ (2006) The marine viromes of four oceanic regions. PLoS Biol 4:2121-2131

5. Baltimore D (1971) Expression of animal virus genomes. Bacteriol Rev 35:235-241

6. Fiers W, Contreras R, Duerinck F, Haegeman G, Iserentant D, Merregaert J, Minjou W, Molemans F, Raeymaekers A, Vandenberghe A, Volckaert G, Ysebaert M (1976) Complete nucleotidesequence of bacteriophage Ms2-Rna-primary and secondary structure of replicase gene. Nature 260:500-507

7. Goldbach RW (1986) Molecular evolution of plant RNA viruses. Annu Rev Phytopathol 24:289-310

8. Gorbalenya AE (1995) Origin of RNA viral genomes; approaching the problem by comparative sequence analysis. In: Gibbs AJ, Calisher CH, Garcia-Arenal F (eds) Molecular basis of virus evolution. Cambridge University Press, Cambridge, pp 49-66

9. Gorbalenya AE, Pringle FM, Zeddam JL, Luke BT, Cameron CE, Kalmakoff J, Hanzlik TN, Gordon KH, Ward VK (2002) The palm subdomain-based active site is internally permuted in viral RNAdependent RNA polymerases of an ancient lineage. J Mol Biol 324:47-62

10. Gorbalenya AE, Snijder EJ, Spaan WJ (2004) Severe acute respiratory syndrome coronavirus phylogeny: toward consensus. J Virol 78:7863-7866

11. Gorbalenya AE, Enjuanes L, Ziebuhr J, Snijder EJ (2006) Nidovirales: evolving the largest RNA virus genome. Virus Res 117:17-37
12. Hatfull GF, Hunters SEAP, My K-NRITH, Educ PHIR (2012) Complete genome sequences of 138 mycobacteriophages. J Virol 86:2382-2384

13. Kamer G, Argos P (1984) Primary structural comparison of Rnadependent polymerases from plant, animal and bacterial-viruses. Nucleic Acids Res 12:7269-7282

14. King AMQ, Adams MJ, Carstens EB, Lefkowitz EJ (eds) (2012) Virus Taxonomy, Classification and Nomenclature of Viruses. Ninth Report of the International Committee on Taxonomy of Viruses. Elsevier, Academic Press, Amsterdam

15. Koonin EV, Gorbalenya AE (1989) Evolution of RNA genomesdoes the high mutation-rate necessitate high-rate of evolution of viral-proteins? J Mol Evol 28:524-527

16. Koonin EV, Wolf YI, Nagasaki K, Dolja VV (2008) The big bang of picorna-like virus evolution antedates the radiation of eukaryotic supergroups. Nat Rev Microbiol 6:925-939

17. Lauber C, Gorbalenya AE (2012) Partitioning the genetic diversity of a virus family: approach and evaluation through a case study of picornaviruses. J Virol 86:3890-3904

18. Lauber C, Gorbalenya AE (2012) Toward genetics-based virus taxonomy: comparative analysis of a genetics-based classification and the taxonomy of picornaviruses. J Virol 86:3905-3915

19. Lauber C, Gorbalenya AE (2012) Genetics-based classification of filoviruses calls for expanded sampling of genomic sequences. Viruses Basel 4:1425-1437

20. Le Gall O, Christian P, Fauquet CM, King AMQ, Knowles NJ, Nakashima N, Stanway G, Gorbalenya AE (2008) Picornavirales, a proposed order of positive-sense single-stranded RNA viruses with a pseudo- $T=3$ virion architecture. Arch Virol 153:715-727

21. Lwoff A, Tournier P, Horne R (1962) System of viruses. Cold Spring Harb Sym Quant Biol 27:51-55

22. Nga PT, Parquet MD, Lauber C, Parida M, Nabeshima T, Yu FX, Thuy NT, Inoue S, Ito T, Okamoto K, Ichinose A, Snijder EJ, Morita K, Gorbalenya AE (2011) Discovery of the first insect nidovirus, a missing evolutionary link in the emergence of the largest RNA virus genomes. PLoS Pathog 7:e1002215

23. Sanger F, Coulson AR, Friedmann T, Air GM, Barrell BG, Brown NL, Fiddes JC, Hutchison CA, Slocombe PM, Smith M (1978) Nucleotide-sequence of bacteriophage-Phi-X174. J Mol Biol 125:225-246

24. Strauss JH, Strauss EG (1988) Evolution of RNA viruses. Annu Rev Microbiol 42:657-683

25. Toh H, Hayashida H, Miyata T (1983) Sequence homology between retroviral reverse transcriptase and putative polymerases of hepatitis B virus and cauliflower mosaic virus. Nature (Lond) 305:827-829

26. Van Regenmortel MH, Maniloff J, Calisher C (1991) The concept of virus species. Arch Virol 120:313-314

27. Van Regenmortel MHV (2018) The species problem in virology. Adv Virus Res 100:1-18

28. Webster CL, Longdon B, Lewis SH, Obbard DJ (2016) Twentyfive new viruses associated with the drosophilidae (Diptera). Evol Bioinform Online 12:13-25

29. Wildy P (1971) Classification and nomenclature of viruses. First report of the international committee on nomenclature of viruses. Monographs in virology, vol 5. Karger, Basel

30. Zeddam JL, Gordon KHJ, Lauber C, Alves CAF, Luke BT, Hanzlik TN, Ward VK, Gorbalenya AE (2010) Euprosterna elaeasa virus genome sequence and evolution of the Tetraviridae family: emergence of bipartite genomes and conservation of the VPg signal with the dsRNA Birnaviridae family. Virology 397:145-154 